\title{
Metode Fuzzy Logic Untuk Evaluasi Kinerja Pelayanan Perawat ( Studi Kasus : RSIA Siti Hawa Padang )
}

\author{
Syaeful Anas Aklani \\ Prodi Pendidikan Informatika, STKIP PGRI Sumbar \\ aklani@gmail.com
}

http://dx.doi.org/10.22202/jei.2014.v1i1.1435

\begin{abstract}
ABSTRAK
On the Eve RSIA Hospital Padang, Nurse is providing primary care and first at the hospital before the doctor, with a good performance and a professional nurse the hospital can provide maximum service to patients or visitors to the Padang and Eve RSIA yet a way to assess the performance of nursing care so the management can not determine what policies need to be taken to evaluate the performance of nurses, based on this and the above information, the author tries to create and design a fuzzy logic to assist management in evaluating the performance of hospital nurses in service. So the evaluation is expected and help assess the performance of management and employees to nurse and take the next step what the results of the performance of nurses there had been no evaluation of the performance of the nursing service. This is an interesting writer to investigate and develop, assess all the existing problems in order to solve the problem.
\end{abstract}

Keywords: Fuzzy Logic, Artificial Intelligence, Nursing

\section{PENDAHULUAN}

Logika fuzzy merupakan salah satu komponen pembentuk soft computing. Logika fuzzy pertama kali diperkenalkan oleh Prof. Lotfi A. Zadeh padatahun 1965. Dasar dari logika fuzzy adalah teori himpunan fuzzy. Pada teori himpunan fuzzy, peranan derajat keanggotaan sebagai penentu keberadaaan elemen dalam suatu himpunan sangatlah penting. Nilai keanggotaan atau derajat keanggotaan atau membership function menjadi ciri utama dari penalaran dengan logika fuzzy tersebut

Profesi keperawatan merupakan suatu profesi yang komplek dan beragam. Perawat berpraktek yang menuntut aspek keperawatan dan peran perawat yang berbeda, selain itu seseorang bisa menjadi perawat melalui berbagai jalur pendidikan keperawatan dan berbagai kesempatan mengembangkan karier sepanjang perawat meningkatkan kinerja dan pendidikannya dan meningkatkan kemampuan klinisnya

Penulis dalam hal ini menggunakan metode mamdani dibandingkan dengan metode metode yang lain karena ada beberapa kelebihan metode mamdani dan sesuai digunakan dalam penelitian untuk mengevaluasi pelayanan kinerja perawat diantaranya adalah pembentukan himpunan fuzzy yang sesuai dengan kebutuhan dalam penelitian, komposisi aturan aturan yang sesuai dan penegasan (defuzy) untuk mencari nilai yang bergerak secara halus sehingga perubahan dari suatu himpunan fuzzy juga akan berjalan secara halus dan lebih mudah dalam perhitungan.

\section{Pembahasan}


Fuzzy Logic

Logika fuzzy merupakan salah satu komponen pembentuk soft computing. Logika fuzzy pertama kali diperkenalkan oleh Prof. Lotfi A. Zadeh padatahun 1965. Dasar dari logika fuzzy adalah teori himpunan fuzzy. Pada teori himpunan fuzzy, peranan derajat keanggotaan sebagai penentu keberadaaan elemen dalam suatu himpunan sangatlah penting. Nilai keanggotaan atau derajat keanggotaan atau membership function menjadi ciri utama dari penalaran dengan logika fuzzy tersebut.

Dalam banyak hal, logika fuzzy digunakan sebagai suatu cara untuk memetakan permasalahan dari input menuju output yang diharapkan. Beberapa contoh yang dapat diambil antara lain (Dini Rusmiyati Andari, 2009 ) :

1) Manajer pergudangan mengatakan kepada manajer produksi seberapa banyak persediaan barang pada akhir minggu ini, kemudian manajer produksi akan menetqapkan jumlah barang yang akan diproduksi esok hari.

2) Seorang pegawai melakukan tugasnya dengan kinerja yang sangat baik, kemudia atas akan memberikan reward, yang sesuai dengan kinerja pegawai tersebut.

1.1 Fuzzy Mamdani

Metode mamdani sering dikenal dengan metode Max-min. Metode ini diperkenalkan oleh Ebrahim Mamdani pada tahun 1975. Untuk mendapatkan output, diperlukan 4 tahapan (Fithriani Matondang dkk, 2010) :

1) Pembentukan himpunan fuzzy
Pada metode mamdani baik variabel input maupun variabel output dibagi menjadi satu atau lebih himpunan fuzzy.

2) Aplikasi fungsi implikasi

Pada metode mamdani, fungsi implikasi yang digunakan adalah $\min$

3) Kompisisi aturan

Tidak seperti penalaran momoton, apabila sistem terdiri dari beberapa aturan, maka inferensi diperoleh dari kumpulan dan kolerasi. Ada tiga metode yang digunakan dalam melakukan inferensi sistem fuzzy, yaitu max, additive dan probabilistik OR (probor).

\section{Metode Max ( Maximum)}

Pada metode ini, solusi himpunan fuzzy diperoleh dengan cara mengambil nilai maksimum atruan, kemudian menggunakannya untuk memodifikasi daerah fuzzy, dan mengaplikasikannya ke output dengan menggunakan operator OR (union). Jika semua proposisi telah dievaluasi, maka output akan berisi suatuhimpunan fuzzy yang merefleksikan komtribusi dari tiap tiap proposisi. Secara umum dapat dituliskan :

$\mu \mathrm{sf}[\mathrm{xi}]=\max (\mu \mathrm{usf}[\mathrm{Xi}], \mu \mathrm{kf}[\mathrm{Xi}])$

Dengan : $\mu \mathrm{sf}[\mathrm{Xi}] \quad=$ nilai

keanggotaannya solusi fuzzy sampai aturan ke I $\mu \mathrm{kf}[\mathrm{Xi}]=$ =nilai keanggotaan konsekuan fuzzy aturan ke i

Misalkan ada 3 aturan (proposisi) sebagai berikut :

[R1] IF Biaya Produksi RENDAH and Permintaan NAIK THEN Produksi Barang BERTAMBAH ; 
[R2] IF Biaya Produksi STANDARTHEN Produksi Barang NORMAL;

[R3] IF Biaya Produksi TINGGI And Permintaan TURUN THEN Produksi barang BERKURANG;

Proses inferensi dengan menggunakan metode Max dalam melakukan komposisi ini sering disebut dengan nama $M A X-M I N$ atau MIN-MAX atau MAMDAI

Metode Additive (Sum)

Pada metode ini, solusi himpunan fuzzy diperoleh dengan cara melakukan boundedsum terhadap semua output daerah fuzzy secara umum dituliskan :

$\mu_{\text {sf }}\left(\mathbf{x}_{\mathbf{i}}\right)=\min \left(1, \mu_{\mathrm{sf}}\left(\mathbf{x}_{\mathbf{i}}\right)+\mu_{\mathrm{kf}}\left(\mathbf{x}_{\mathrm{i}}\right)\right.$

dengan :

$\mu_{\mathrm{sf}}\left[\mathrm{X}_{\mathrm{i}}\right] \quad=$ nilai keanggotaannya solusi fuzzy sampai aturan ke $\mathrm{i}$

$\mu_{\mathrm{kf}}\left[\mathrm{X}_{\mathrm{i}}\right] \quad=$ nilai keanggotaan konsekuan fuzzy aturan ke i

Metode Probalistik OR (probor)

Pada metode ini, solusi himpunan fuzzy diperoleh dengan cara melakukan product terhadap semua output daerah fuzzy. Secara umum dituliskan :

$\mu_{\text {sf }}\left(\mathbf{x}_{\mathrm{i}}\right)=\left(\mu_{\mathrm{sf}}\left(\mathbf{x}_{\mathrm{i}}\right)+\mu_{\mathrm{kf}}\left(\mathbf{x}_{\mathrm{i}}\right)\right)-\left(\mu_{\mathrm{sf}}\left(\mathbf{x}_{\mathrm{i}}\right)^{*} \mu_{\mathrm{kf}}\left(\mathbf{x}_{\mathrm{i}}\right)\right)$

dengan :

$\mu_{\mathrm{sf}}\left[\mathrm{X}_{\mathrm{i}}\right] \quad=$ nilai keanggotaannya solusi fuzzy sampai aturan ke i

$\mu_{\mathrm{kf}}\left[\mathrm{X}_{\mathrm{i}}\right] \quad=$ nilai keanggotaan konsekuan fuzzy aturan ke i

Penegasan (defuzzy)
Input proses defuzzifikasi adalah suatu himpunan fuzzy yang diperoleh dari komposisi aturasn aturan fuzzy, sedangkan output yang dihasilkan merupakan suatu bilangan pada domain himpunan fuzzy dalam range tertentu, maka harus dapat diambil suatu nilai crisp tertentu sebagai output seperti pada gambar ;

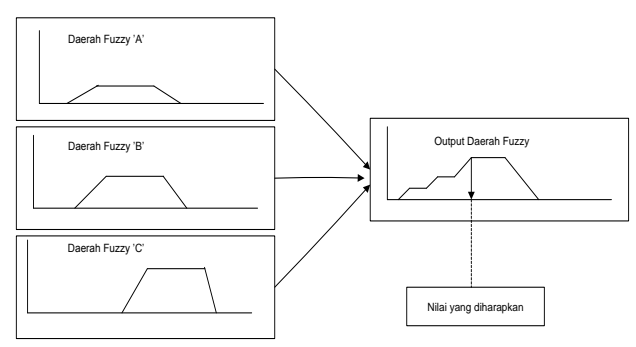

Gambar. alur fuzzy

1.2 Keperawatan

Tujuan evaluasi kinerja adalah untuk memperbaiki atau meningkatkan kinerja organisasi melalui peningkatan kinerja dari SDM organisasi. Secara lebih spesifik, tujuan evaluasi kinerja sebagaimana dikemukakan (Mangkunegara, 2005) adalah

a) Meningkatkan saling pengertian antara karyawan tentang persyaratan kinerja

b) Mencatat dan mengakui hasil kerja seorang karyawan, sehingga mereka termotivasi untuk berbuat yang lebih baik, atau sekurang-kurangnya berprestasi sama dengan prestasi yang terdahulu.

c) Memberikan peluang kepada karyawan untuk mendiskusikan keinginan dan aspirasinya dan meningkatkan kepedulian terhadap karier atau terhadap pekerjaan yang diembannya sekarang. 
d) Mendefinisikan atau merumuskan kembali sasaran masa depan, sehingga karyawan termotivasi untuk berprestasi sesuai dengan potensinya.

e) Memeriksa rencana pelaksanaan dan pengembangan yang sesuai dengan kebutuhan pelatihan, khusus rencana diklat, dan kemudian menyetujui rencana itu jika tidak ada hal-hal yang perlu diubah.

Kriteria proses dalam evakuaasi keperawatan adalah menyusun perencanaan dalam evaluasi dari hasil intervensi secara komperehensif, tepat waktu dan terus menerus,menggunakan data dasar dan respon klien dalam mengukur perkembangan kearah pencapaian tujuan, memvalidasi dan menganalisis data baru dengan teman sejawat, bekerja sama dengan klien dan keluarga untuk memodifikasi rencana asuhan keperawatan dan mendokumentasikan hasil evaluasi dan modifikasi perencanaan (Depkes, 2001).

Dalam penilaian kinerja perawat ada beberapa indikator hal yang perlu dijadikan alat ukur untuk penilaian perawat di antaranya adalah :

1) Motivasi : memiliki minat untuk melanjutkan pendidikan formal minimal S1 Keperawatan, dan datang aktif dalam mengikuti kegiatan kegiatan ilmiah, wajah cerah, senyum dan bersahabat, berjalan tegak, cepat dan pandangan kedepan.

2) Keterlibatan : Menjadi panitia kegiatan keperawatan, menjadi panitia kegiatan tingkat rumah sakit, menjadi tema yang ada dikeperawatan.

3) Tanggung Jawab : Kesalahan identifikasi pasien, kesalahan pemberian obat, kejadian pasien jatuh, risiko infeksi nosolomial.

4) Disiplin : jam datang dan jam pulang tepat waktu dan berseragam sesuai dengan tempat bekerja di rumah sakit.

5) Kompetensi : Diagnosa keperawatan, standar operating prosedur, rencana kerja.

6) Loyalitas : Program rotasi, program bidang, program ruang dan hubungan dengan atasan

7) Tidak tercela : terlibat kasus etik, komplain pasien, konflik dengan teman

8) Manajemen : Melakukan orientasi perawat baru, perawat magang dan mahasiswa, membuat progam pengembangan staff, melakukan penilaian kinerja, melakukan manajemen tenaga.

Jadi ada beberapa faktor dalam menentukan penilaian kinerja perawat untuk memberikan laporan hasil yang sesuai yang di lapangan

\subsection{Analisa Data}

Dalam analisa ini penulis menganalisa dan mengelompok kelompokkan data untuk memudahkan dalam mengerjakan perancangan sistem yang telah direncanakan sebelumnya sesuai dengan variabel variabel yang dibutuhkan, guna untuk menganalisa data yang diperlukan dalam perancangan sistem ini.

FIS (Fuzzy Inference System) dibangun dengan dua metode, yaitu mamdani dan metode sugeno, Keluaran fuzzy mamdani berupa fuzzy set dan bukan sekedar inverse dari fungsi keanggotaan output. Dengan kata lain 
untuk menghitung harga keluaran dari IF-THEN rule, metode mamdani harus menghitung luas dibawah kurva fuzzy set pada bagian keluaran (THEN-part). Selanjutnya dalam proses defuzzifikasi, metode mamdani harus menghitung rata rata (centroid) luas yang diboboti dari semua fuzzy set keluaran dari rule, kemudian mengisikan rata-rata tersebut ke variabel keluaran FIS

Di dalam tahap menganalisa dan merancang sistem terdapat 4 variabel yang digunakan dan di perlukan antara lain : Cara Kerja Perawat, Sopan Santun, Perilaku, Penampilan dan Cara Berjalan ditambah satu variabel Output Evaluasi Kinerja. Seperti pada gambar berikut ini ;

\section{Analisa data untuk Variabel Cara Kerja Perawat}

Di dalam Variabel cara kerja perawat terdapat input nilai rata rata dari variabel Cara kerja perawat adalah sebagai berikut : (1) Kenyamanan, (2) Keterampilan, (3) Kerjasama, (4) Ketelitian, (5) Keluhan Pasien

Untuk nilai Variabel cara kerja perawat di bagi menjadi 4 bagian diantaranya adalah :

Tabel 1. Semesta Pembicaraan

\begin{tabular}{|l|l|l|}
\hline $\begin{array}{l}\text { Semesta } \\
\text { Pembicaraan }\end{array}$ & $\begin{array}{l}\text { Himpunan } \\
\text { Fuzzy }\end{array}$ & $\begin{array}{l}\text { Domain } \\
\text { Nilai }\end{array}$ \\
\hline \multirow{4}{*}{ Nilai 0-100 } & Tidak pernah & $0-50$ \\
\cline { 2 - 3 } & $\begin{array}{l}\text { Kadang- } \\
\text { kadang }\end{array}$ & $40-70$ \\
\cline { 2 - 3 } & Sering & $60-90$ \\
\cline { 2 - 3 } & Selalu & $80-100$ \\
\hline
\end{tabular}

Diagram Membership Function dapat untuk variabel Cara Kerja Perawat, dapat dilihat pada gambar ini :

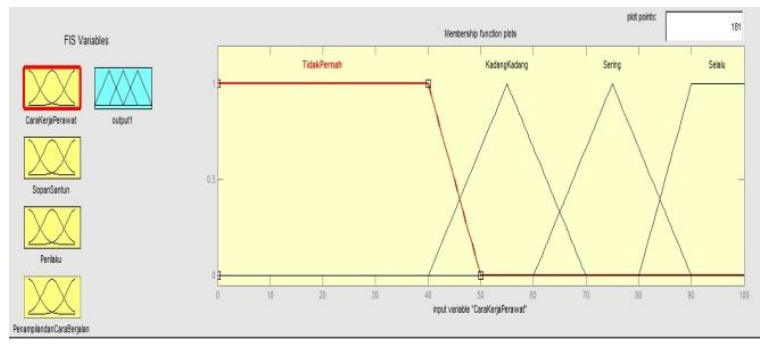

Gambar. hasil fuzzy

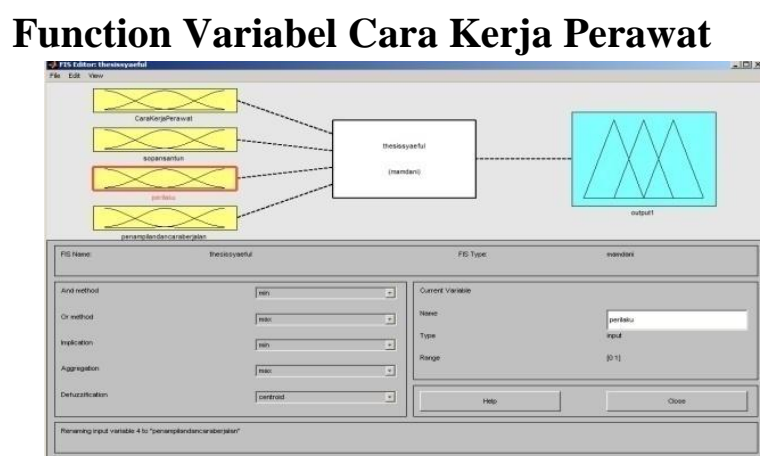

Gambar. Logika FUZZY

Terdapat 4 himpunan fuzzy untuk variabel Cara Kerja Perawat antara lain : Selalu, Sering, Kadang-kadang dan tidak pernah. Himpunan fuzzy tidak pernah memiliki domain (0-50) dengan derajat keanggotaan kurang tertinggi terdapat pada nilai 40 , jika nilai variabel semakin tinggi dan melebihi nilai 40 maka semakin mendekati kadang kadang, himpunan fuzzy kurang di presentasikan dengan bahu kiri, himpunan fuzzy kurang sebagai berikut :

$$
\mu_{\text {tidakpernah }}\left[X_{1}\right]=\left\{\begin{array}{c}
1 ; X_{I} \leq 40 \\
\frac{40-X_{1}}{5} ; 40 \leq X_{I} \leq 50(1 \\
0 ; X_{1} \geq 0
\end{array}\right.
$$




\section{Jurnal Edik Informatika}

ISSN : 2407-0491

E-ISSN : 2541-3716

Penelitian Bidang Komputer Sains dan Pendidikan Informatika V1.i1(35-43)

Untuk himpunan fuzzy kadang kadang mempunyai domain $(40-70)$ dengan derajat keanggotan kadang kadang, tertinggi nilainya terdapat pada 55 , jika nilai variabel semakin tinggi dan melebihi nilai 55 maka semakin mendekati sering. Himpunan fuzzy kadang kadang di implementasikan dengan fungsi keanggotaan segitiga, himpunan fuzzy kadang kadang sebagai berikut ;

$$
X_{l} \geq 70\left\{\begin{array}{c}
0 ; X_{1} \leq 40 \text { atau } \\
\mu_{\text {kadang kadang }}\left[X_{1}\right]=\frac{X_{1}-40}{15} ; 40 \leq X_{1} \leq 55 \\
\frac{70-X_{1}}{15} ; 55 \leq X_{1} \leq 70
\end{array}\right.
$$

Untuk himpunan fuzzy sering mempunyai domain $(60-90)$ dengan derajat keanggotan sering, tertinggi nilainya terdapat pada 75 , jika nilai variabel semakin tinggi dan melebihi nilai 75 maka semakin mendekati selalu. Himpunan fuzzy sering di implementasikan dengan fungsi keanggotaan segitiga, himpunan fuzzy sering sebagai berikut ;

$\mu_{\text {sering }}\left[X_{1}\right]=\left\{\begin{array}{l}0 ; X_{1} \leq 60 \text { atau } X_{l} \geq 90 \\ \frac{x_{1}-60}{15} ; 60 \leq X_{1} \leq 75 \\ \frac{90-X_{1}}{15} ; 75 \leq X_{1} \leq 90\end{array}\right.$

Sedangkan untuk himpunan fuzzy selalu mempunyai domain $(80-100)$ dengan derajat keanggotaan selalu, ter

tinggi nilainya terdapat pada 90, apabila nilai kurang dari 90 maka mendekati sering, himpunan fuzzy selalu di presentasikan dengan bahu kanan

$$
\mu_{\text {selalu }}\left[\mathrm{X}_{1}\right]=\frac{x_{1}-80}{10}\left\{\begin{array}{c}
0 ; X_{1} \leq 80 \\
70 \leq X_{1} \leq 90 \\
1 ; X_{1} \geq 90
\end{array}\right.
$$

\subsection{Perancangan Sistam}

Pada bagian ini penulis merancang sistem fuzzy yang digunakan dalam pengembangan sistem untuk analisa evaluasi kinerja perawat seperti pada model analisa diatas, adapun bagan model sistem yang di rancang seperti ini ;

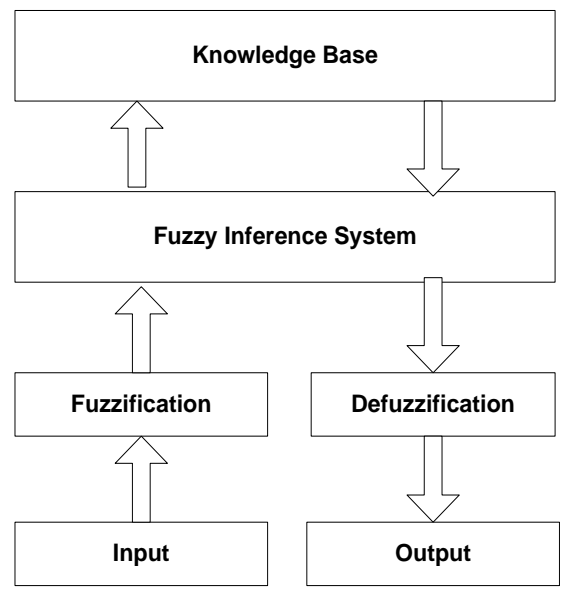

Gambar. Penalaran fuzzy

Contoh Penerapan Fuzifikasi dalam program

Total Laporan Kuisioner Secara Keseluruhan Cara Kerja Perawat : 70, Sopan 
Santun : 75, Perilaku : 89 dan Penampilan dan Cara Berjalan : 80

Cara Kerja Perawat $=70$

$\mu_{\text {tidakpernah }}[70]=\frac{40-X_{1}}{5}\left\{\begin{array}{c}1 ; X_{1} \leq 40 \\ 40 \leq X_{1} \leq 50 \\ 0 ; X_{1} \geq 0\end{array}\right.$

$\mu_{\text {kadang kadang }}[70]$
$=\frac{70-40}{15} ; 40 \leq 64 \leq 55$
$\frac{70-70}{15} ; 55 \leq 64 \leq 70$

$=0$

$\mu_{\text {sering }}[70]=\left\{\begin{array}{l}0 ; X_{1} \leq 60 \text { atau } X_{1} \geq 90 \\ \frac{70-60}{15} ; 60 \leq X_{1} \leq 75 \\ \frac{90-70}{15} ; 75 \leq X_{1} \leq 90\end{array}\right.$

$\mu_{\text {selalu }}[70]=\frac{x_{1}-80}{10}\left\{\begin{array}{l}0 ; X_{1} \leq \\ ; 70 \leq X_{1} \leq 90 \\ 1 ; X_{l} \geq 90\end{array}\right.$

1. Sopan Santun $=75$

$\mu_{\text {tidakpernah }}[75]=\left\{\begin{array}{l}1 ; 75 \leq 30 \\ \frac{30-75}{5} ; 30 \leq X_{3} \leq 40\end{array}\right.$

$$
\mu_{\text {kadang kadang }}\left[7 5 \left\{\begin{array}{c}
0 ; X_{3} \leq 30 \text { atau } X_{3} \geq 60 \\
\frac{X_{\mathrm{g}}-30}{15} ; 30 \leq X_{3} \leq 45 \\
\frac{60-75}{15} ; 45 \leq X_{3} \leq 60
\end{array}\right.\right.
$$

$$
0 ; 75 \leq 50 \text { atau } X_{3} \geq 90
$$$$
\mu_{\text {sering }}[75]=\left\{\begin{array}{r}
\frac{75-50}{20} ; 50 \leq X_{3} \leq 70 \\
\frac{90-75}{20} ; 70 \leq X_{3} \leq 90 \\
=0.75
\end{array}\right.
$$

$\mu_{\text {selalu }}\left[\mathrm{X}_{3}\right]\left\{\begin{array}{c}0 ; X_{3} \leq 70 \\ =\frac{X_{\mathrm{s}}-70}{15} ; 70 \leq X_{3} \leq 85\end{array}\right.$

$$
1 ; X_{3} \geq 85
$$

\section{Perilaku $=89$}

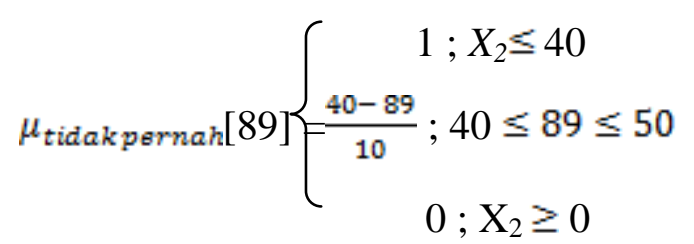

$$
\begin{aligned}
& X_{2} \geq 70 \quad\left\{\begin{array}{c}
0 ; X_{2} \leq 40 \text { atau } \\
\mu_{\text {kadang kadang }}[89]=\frac{X_{2}-40}{15} ; 40 \leq X_{2} \leq 55
\end{array}\right. \\
& \frac{70-X_{2}}{15} ; 55 \leq X_{2} \leq 70
\end{aligned}
$$

$$
\mu_{\text {sering }}[89]=\left\{\begin{array}{l}
0 ; X_{2} \leq 60 \text { atau } X_{2} \geq 90 \\
\frac{89-60}{15} ; 60 \leq X_{2} \leq 75 \\
\frac{90-89}{15} ; 75 \leq X_{2} \leq 90
\end{array}\right.
$$




\section{Jurnal Edik Informatika}

ISSN : 2407-0491

E-ISSN : 2541-3716

Penelitian Bidang Komputer Sains dan Pendidikan Informatika V1.i1(35-43)

$$
=0,06
$$

$$
\mu_{\text {selalu }}[89]=\begin{gathered}
0 ; 89 \leq 80 \\
=\frac{89-80}{10} ; 70 \leq 89 \leq 90 \\
1 ; 89 \geq 90
\end{gathered}
$$

\section{Penampilan dan Cara Berjalan $=$} 80

$$
\mu_{\text {tidakpernah }}[80]=\left\{\begin{array}{c}
1 ; 80 \leq 30 \\
\frac{30-x_{4}}{5} ; 30 \leq X_{4} \leq 40 \\
0 ; X_{4} \geq 0
\end{array}\right.
$$$$
\mu_{\text {kadang kadang }}[80]=\begin{gathered}
0 ; 80 \leq 30 \text { atau } X_{4} \geq 60 \\
=\frac{80-30}{15} ; 30 \leq X_{4} \leq 45 \\
\frac{60-80}{15} ; 45 \leq X_{4} \leq 60
\end{gathered}
$$$$
\mu_{\text {sering }}[80]=\left\{\begin{array}{c}
0 ; X_{4} \leq 50 \text { atau } X_{4} \geq 90 \\
\frac{x_{4}-50}{20} ; 50 \leq X_{4} \leq 70
\end{array}\right.
$$$$
\frac{90-80}{20} ; 70 \leq X_{4} \leq 90
$$$$
=0,5
$$

$$
\mu_{\text {selalu }}[80]\left[\begin{array}{c}
0 ; 80 \leq 70 \\
=\frac{80-70}{15} ; 70 \leq 80 \leq 85 \\
1 ; X_{4} \geq 85
\end{array}\right.
$$

\section{Penalaran (Inferensi)}

Tahap ini merupakan penentuan rule-rule dari sistem logika fuzzy, aturan-aturan dapat dibentuk untuk menyatakan relasi antara input dan output. Tiap aturan merupakan implementasi. Operator yang digunakan untuk menghubungkan aturan-aturan input adalah operator And yang menggambarkan antara input-output adalah IF - THEN

If (CaraKerjaPerawat is Sering) and (SopanSantun is Selalu) and (Perilaku is Sering) and (PenampilandanCaraBerjalan is Sering) then (output1 is Baik)

$\alpha$ - hasil penilaian perawat $=\mu$ CKPsering $\cap$ $\mu$ SSselalu $\cap \mu$ PKsering $\cap$ PCBsering

$$
=\mu \mathrm{CKPsering}(70) \cap \mu \mathrm{SSselalu}(75)
$$$$
\mu \text { PKsering }(89) \cap \text { PCBsering(80) }
$$$$
=\min (0,67 ; 0,75 ; 0,06 ; 0,50)
$$$$
=0,06
$$

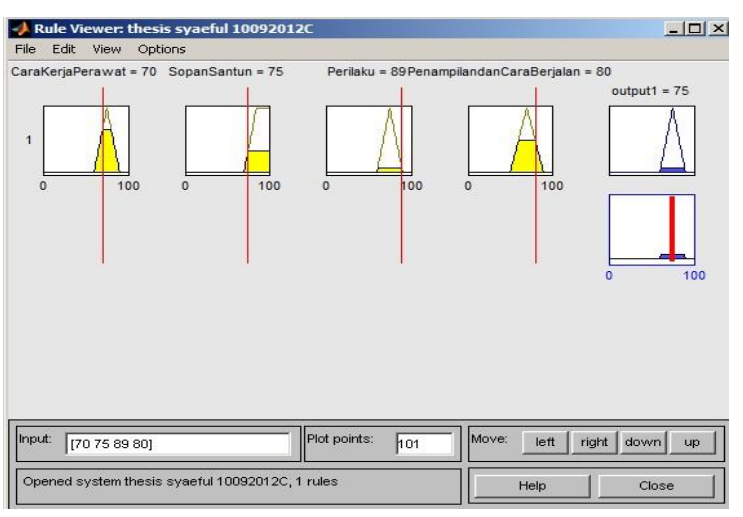

\section{Gambar 4.9 Hasil Penalaran}

\section{Defuzifikasi}

Tahap ini disebut juga tahap penegasan input dan proses. Penegasan ini adalah suatu himpunan kabur yang diperoleh dari komposisi aturan-aturan kabur, sedangkan output yang dihasilkan merupakan suatu bilangan pada domain himpunan kabur tersebut.

Hasil Rule seperti data diatas adalah ; 


$$
\begin{aligned}
& Z=\frac{70.0,67+75.0,75+89.0,06+80.0,5}{0,67+0,75+0,06+0,5} \\
& Z=\frac{46,9+56,25+5,34+40}{1,98} \\
& Z=\frac{148,49}{1,98} \\
& Z=74,99
\end{aligned}
$$

Maka dari percobaan diatas terdapat hasil nilai 74,99 yang termasuk dalam kinerja perawat yang Baik

\section{KESIMPULAN}

Dari hasil penelitian tersebut maka metode fuzzy logic untuk penelian kinerja perawat di rumah sakit, sesuai hasil yang di inginkan dan metode fuzzy logic dapat digunakan untuk penelian kinerja perawat.

\section{DAFTAR PUSTAKA}

Kusuma Dewi, Aplikasi Logika Fuzzy Untuk Pendukung Keputusan Edisi 2, Graha Ilmu, 2010.

Naba Agus, Belajar Cepat Fuzzy Logic Menggunakan Matlab. Penerbit Andi, 2009

Arifah Durratul Enny, Jurnal Aplikasi Metode Mamdani Dalam Penentuan Jumlah Produksi. ITS, 2010

Marpaung Bintang Sahala, Jurnal Gambaran Kepuasan Pasien Terhadap Pelayanan Pelayanan Keperawatan di Ruang Rawat Inap di Rumah Sakit XYZ
Tahun 2009, Sekolah Tinggi Ilmu Ekonomi Kesayuan Bogor, 2010

Animoto Toto, Dkk , Jurnal Evaluasi Kinerja Karyawan Menggunakan Metode Fuzzy Linier Progamming, STIE Indonesia, 2010 